\title{
THEORY BUILDING TRENDS IN INTERNATIONAL MANAGEMENT RESEARCH: AN ARCHIVAL REVIEW OF PREFERRED METHODS
}

\author{
H S Kriek \\ Graduate School of Business Leadership, University of South Africa \\ Dave Beaty \\ Gordon Institute of Business Science, University of Pretoria \\ Stella Nkomo \\ Graduate School of Business Leadership, University of South Africa
}

\begin{abstract}
A number of distinguished scholars believe that for theory development to occur within a field, qualitative research must precede quantitative research in order for the field to progress toward maturity. The purpose of this study was to investigate the international management literature from 1991-2007 to ascertain current levels of use of qualitative, quantitative, conceptual and joint (quantitative and qualitative) research methods in the field. Results indicate that scholars employ quantitative methods more than qualitative methods. The implications of these findings for future theory development and the generation of context relevant international management knowledge are discussed.
\end{abstract}

JEL D83

\section{1 \\ Introduction}

International management developed as an academic field from the broader umbrella field of international business and is recognised as subfield in its own right (Jack, Calás, Nkomo, \& Peltonen, forthcoming; Shenkar, (2004)). While some viewed the emergence of discipline specific foci (e.g. international management, international marketing, and international finance) as a narrowing of international business, its purpose was to develop in-depth theoretical and practical understanding of the complex management aspects of doing business in an international context (Peterson, 2004). Although there is still residual debate about the boundaries of international management, international management is defined as encompassing the sub-areas of international strategy, human resource management, organisational theory, organisational behaviour, ethics, and industrial relations, and joint ventures (Mendenhall, Beaty, \& Oddou, 1993; Peterson, 2004). In short, international management is concerned with the management of an international business or multinational corporation.

One of the consistent themes in international management has been the need to build management theory that reflects the unique reality of different cultures and contexts in the global business environment (Boyacigiller \& Adler, 1991; Doktor, Tung \& Von Glinow, 1991; Hofstede, 1980; Hofstede, 2001; Lewis, 2000). Despite this call, however, evidence, exists that the majority of management theories is still formulated in North America or Western Europe and exported abroad (Gregerson, Morrison \& Black, 1998; Hofstede, 2001; House, Hanges, Javidan, Dorfman \& Gupta 2004; Kirkman \& Law, 2005; Lewis, 2000; Peterson, 2004; Tsui, 2004; Westwood \& Linstead, 2001). Indeed, a number of scholars have challenged the assumption that management theories 
formulated in one country are applicable universally, and have demonstrated in their research that management theories applicable in one country cannot be generalised directly to other countries (e.g. House et al, 2004; Javidan, Stahl, Brodbeck \& Wilderom, 2005).

Yet, progress in developing new context relevant theory in international management has been slow (Tsui, 2004; Peterson, 2004; Porter, 1996). Tsui (2004: 491) points to a number of reasons for this, including the "perception of entry barriers created by disciplinary and paradigmatic preference held by gate keepers of the leading scholarly journals". Another reason offered is the continued domination of international management scholarship by authors from North America (Kirkman \& Law, 2005) despite a slight increase in publications of authors from other parts of the world. A final reason offered is the scarcity of theory building in international management (Mendenhall et al, 1993; Schollhamer, 1975; Tsang \& Kwan, 1999; Tsui, 2004; White, 2002). For example, Mendenhall et al (1993) concluded in a study of international management research from 19841990 that research in the field had produced little in the way of new theory development. White (2002) concluded in a review of Asian management research from 1980-2000 that there is a lack of theory development and contribution to theoretical discourse beyond an audience specifically interested in Asia. White's (2002) conclusion is consistent both with the conclusions of a citation study of 226 articles on management and organisation in the Greater China region from 1984-1999 (Li \& Tsui, 2002), and the recent findings of Beaty, Nkomo, and Kriek (2006) in which they confirmed the dearth of theory building research in the extant management literature in South African academic journals for the period 1994-2004.

While the above discussion suggests the need for more theory building studies in international management research, particularly in global contexts other than North America and Western Europe, an important starting point is to review the current reality in terms of trends in theory building research in the field of international management. One means of assessing these trends is to examine the relative use of qualitative and quantitative research methods in the extant literature. Dennis and Garfield (2003: 297) assert "quantitative research is theory in search of data while qualitative research is data in search of theory." Qualitative field studies provide rich data and a strong base on which to build theory. This view is supported by Cassell and Symon (2006), Cassel, Symon, Beuhring and Johnson (2006), Eisenhardt (1989), Miles and Huberman, (1994), Strauss and Corbin (1990), and Symon and Cassell (1998) who have written extensively on the use of qualitative research methods in building theory. Others assert qualitative research precedes theoretical and empirical research in driving a field to maturity (Bedeian, 1989; Carlie \& Christensen, 2004; Weick, 1989; Van de Ven, 1989). The use of qualitative methods, such as case studies, has long been noted to be especially important in the progression of theoretical knowledge in the applied sciences (Van Fleet \& Beard, 1988). More recently, Tsui (2004) argued that through the use of a grounded theory building approach, authors such as Barker (1993), Barley (1986), Dutton and Dukerich, (1991) and Eisenhardt, (1989) were able to derive new constructs and empirical generalisations that formed the core of a new theory or model. Eisenhardt's (1989) article is viewed as a seminal contribution on the process of inducting theory using case studies. In sum, all of this suggests that there is an intimate relationship between the methodology utilised in conducting international management research and the development of new international management theory.

\section{2 \\ Purpose and research objectives}

The purpose of this study is to ascertain the extent to which theory building trends are occurring in the field of international management. Namely, the interest is in delineating methodological trends in articles published in international management research as one of the indicators of new theory development. In a related study, Mendenhall et al (1993) investigated the status and development of theory building in the field of international management by examining the extent to which qualitative methodologies were 
employed in research conducted over a decade (1984-1990). At the time, their empirical findings confirmed the observations of Schollhammer (1975) and Bedeian (1989) that research in the field of international management had produced little in the way of theory building. Indeed, Mendenhall et al (1993: 151) asserted that the field of international management was "theory thin" and "method driven". Since their study, there has not been a follow up to ascertain whether this trend is continuing, or, if other trends are emerging.

This study replicates the methodology of the Mendenhall et al (1993) study. They argued that international management academic journals are the most likely sources from where most theorists in international management would publish theory building research. Consequently, this research followed a similar research strategy and methodology to examine trends in theory building and research in international management over a sixteen year period (19912007), covering almost two decades of additional research since the original study. The latter review is significant given the renewed call for management scholars to develop good theory and to understand the interplay between theory and method (Van Maanen, Sorensen, \& Mitchell, 2007). Method and theory in a discipline are closely intertwined, with the choice of method influencing the research agenda and the ability to generate theory and new insights in a field (Marschan-Piekkari \& Welch, 2004). At a practical level, management theories are critical to understanding, explaining, and predicting social processes and structures that characterise behaviour in and of organisations (Van Maanen, Sorensen, \& Mitchell, 2007). The development of international management theory in the end should provide managers with the knowledge to effectively manage organisations and people in international contexts.

\section{3}

\section{Research methodology}

The study reviewed research published from 1991-2007 in the same journals reviewed by Mendenhall et al (1993). New journals in the field were excluded for 2 reasons: (1) because we wanted to replicate the Mendenhall et al (1993) research and (2) we would not have been able to cover the same time period since the relatively recent journals do not date back to 1991. The following journals were included: Journal of International Business Studies, Management International Review, Journal of World Business (formerly Columbia Journal of World Business), International Studies of Management and Organisation, and Asia-Pacific Journal of Management. All of these journals are listed as high impact top journals publishing international management research (Harzing, 2008).

It is acknowledged that international management research also appears in traditional management journals. However, despite the call by editors of some of these journals for more international research, few international management articles are published in these journals relative to the international management journals listed above (Eden \& Rynes, 2003; Werner, 2002).

An archival review of the published literature was conducted and each article in the aforementioned journals was examined to identify the general research method employed. This approach is consistent with previous studies seeking to gain an understanding of how a field is evolving (e.g. Krikman \& Law, 2005; Mendenhall et al, 1993). The categories used by Mendenhall et al (1993) were used to assist in the classification of the articles published, namely "conceptual", "qualitative", quantitative, and "joint". While Mendenhall et al (1993) used the label "empirical" to denote methods relying on quantification of data and deduction, we prefer the label "quantitative" since both qualitative and quantitative research are empirical methods of data collection and analysis (Creswell, 2003; Peterson, 2004). The editorial policies of the journals also allowed for non-empirical pieces. Thus, articles were defined as "conceptual" if they were reviews of the literature, essays or critiques of the literature (or what Dreher (2003) refers to as systematic attempts to clarify the explicit and implicit use of concepts), applications of literature findings to business practices or any combination of the above approaches. The distinction here is that 
conceptual articles did not involve the collection of empirical data. "Qualitative" was used if data collection occurred through means such as case studies, interviews, narrative studies, ethnography, archival retrieval, participantobservation and other varieties of qualitative methods. Our approach is consistent with Symon and Cassell's (1998) observation that there is a wide range of qualitative methods available to management scholars. As Denzin and Lincoln (2003) note, qualitative researchers seek answers to questions that stress how social experience is created and given meaning. Qualitative research methods seek to describe, decode, and translate phenomena. Its hallmark is flexibility and sensitivity to the social context in which the data are collected. Qualitative research employs an emic approach that confronts the constraints of the everyday social world. The latter is particularly important if scholars are to develop international management theories reflective of the unique reality of different cultures and contexts.

If measurement and statistical analysis of causal relationships between variables were utilised as the basis for the research method, the article was categorised as "quantitative". Quantitative research seeks a nomothetic or etic science based on probabilities derived from the study of large numbers of randomly selected cases (Creswell, 2003; Denzin \& Linclon, 2003). The last classification approach, "joint" was used if the study employed both "quantitative" and "qualitative" design techniques (Mendenhall et al, 1993) or what is known as triangulation (Opperman, 2000).

To test for interrater reliability, which is the extent to which two or more individuals (coders or raters) agree, each author independently read and categorised the articles using the pre-defined types of research (i.e. conceptual, quantitative, qualitative, and joint). Interrater reliability addresses the consistency of the implementation of a rating or classification system (Carmines \& Zeller, 1991). Next, we compared our category assignments and found 95 percent agreement. Where there were differences, the articles were collectively discussed and appropriately categorised. A majority of differences found were processing errors (i.e. erroneously listing an article in the wrong category column). Interrater reliability addresses the question of consistency among the researchers in assigning each article to the four different types of research. It does not, however, assess validity which would be concerned with the classification system itself. It is important to note we used predefined, well established definitions of each type of research article, suggesting that at a minimum content validity was achieved. Content validity is based on the extent to which a measurement reflects the specific intended domain of content (Carmines \& Zeller, 1991: 20).

Once the categorisation was completed, a statistical analysis was performed to ascertain whether there were significant differences in the research methods utilised. We performed a Chi-square analysis which allows for a test of differences in the cell frequencies of each of the different types of methods (Gravetter \& Wallnau, 2000).

\section{4 Results}

The overall results (see Table 1) indicate the majority of research published in international management journals over the past fifteen years were conceptual articles (37.39 per cent) followed by quantitative studies (26.64 per cent). Studies utilising joint qualitative and quantitative research methodologies were less evident (19.17 per cent) while studies employing qualitative research methodologies were least evident (16.8 per cent). The Chisquare analysis indicated significant differences in the research methods (Chi-square 286.192, d.f. 3). These results were significant at the $\mathrm{p}<.01$ level. 
Table 1

Percentage of total research per type

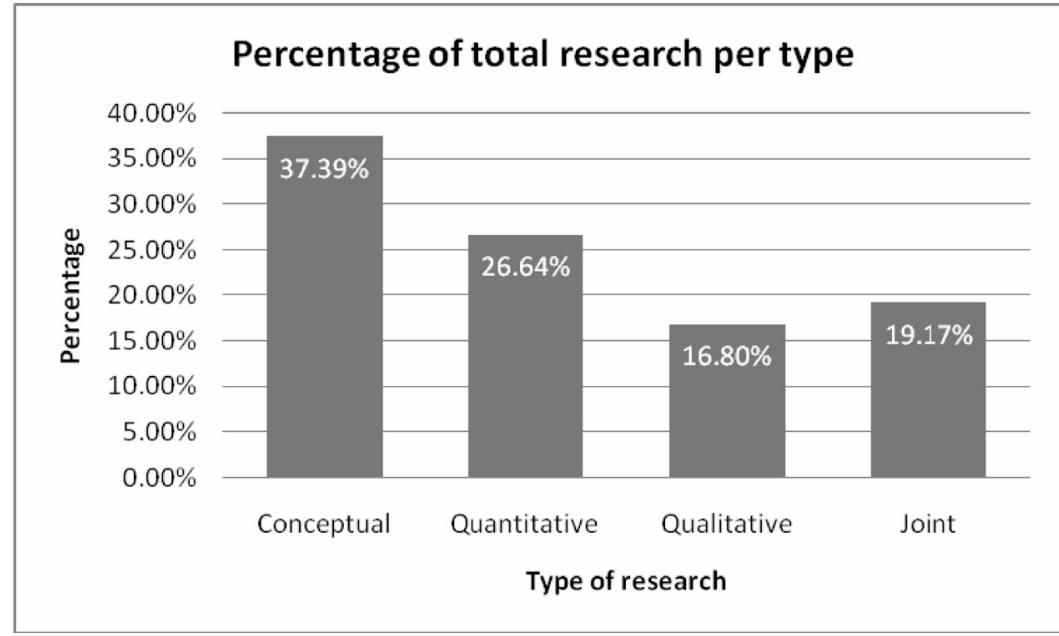

Table 2 presents the results of articles in each of the journals according to the type of research method employed. Articles employing a qualitative methodology were most evident in the Journal of World Business (26.27 per cent) and the International Studies of Management and Organisation ((26.85 per cent). Qualitative research methodologies were least evident in the Management International Review (15.24 per cent), the Asia Pacific Journal of Management (12.95 per cent) and the Journal of International Business Studies (9.39 per cent). Articles employing mainly "joint" methodologies were least represented in two of the five journals surveyed and accounted for no more than 25 per cent of all international management articles published from 19912007. Articles employing quantitative methods were dominant in only one journal (Journal of International Business Studies) of the five journals surveyed over the sixteen year period (see Table 2).
Table 2

Type of research per journal

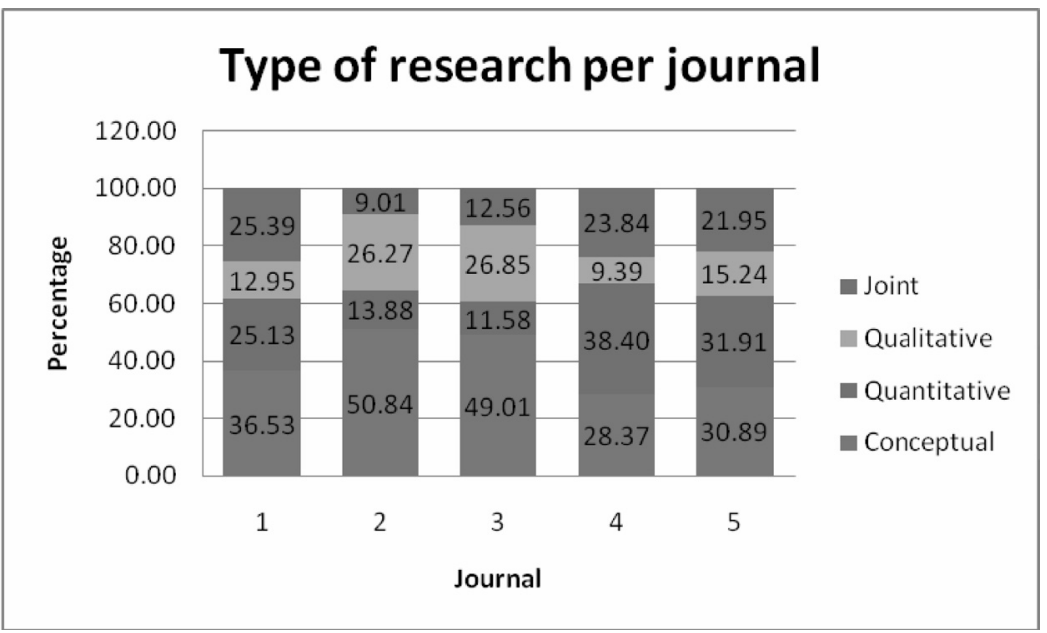

\begin{tabular}{|l|}
\hline Legend \\
$1=$ Asia Pacific \\
Journal of \\
Management \\
$2=$ Columbia Journal \\
of World Business \\
$3=$ International \\
Studies of \\
Management and \\
Organisations \\
$4=$ Journal of \\
International Business \\
Studies \\
$5=$ Management \\
International review
\end{tabular}


5

\section{Conclusions and implications}

The archival data indicate articles published over the past sixteen years in major international management journals employ methodologies skewed towards "quantitative" and "conceptual" research. The findings in this investigation also reveal the trend is more pronounced in some journals relative to others. On the whole, however, the evidence indicates that during the period studied, researchers in international management employed "qualitative" methods and "joint" methodologies in their work less than "quantitative" and "conceptual" approaches. These findings hold a number of implications in terms of driving the international management field towards maturity as well as for South African scholars' contributions in this regard. The latter is particularly important given the increasing call within South Africa for the development of management theories relevant to the country and the continent of Africa.

First, when these research findings are compared and contrasted with the findings of Mendenhall et al (1993), they reveal a consistent trend occurring over two different time periods in terms of the types of research methods employed in articles published in international management related journals. For example, the majority of research methods in articles published from 1984-1990 as reported by Mendenhall et al (1993) were: "conceptual" articles (42.1 per cent), followed by "quantitative" articles (39.74 per cent), "qualitative" articles (14.23 per cent) and least evident were "joint" (qualitative and quantitative) articles (4.17 per cent). Consistent with these trends are the findings of this investigation indicating little has changed in terms of the pattern of the types of research methods used in publications in international management journals from 19841990 and 1991-2007. Trends have remained consistent in spite of a significant body of opinion that has consistently indicated that "qualitative" research is imperative for the generation of theory and new insights in a field and in particular, the development of valid comparative management theories (MarschanPiekkari \& Welch, 2004; Peterson, 2004). The continued dominance of "conceptual" articles raises the question of whether international management scholarship has ran out of steam - focusing on literature reviews and critiques of extant literature. While the latter may suggest disaffection with the existing set of theories, it may underscore the need for new theory development in the field (Buckley, 2002).

As previously indicated, numerous authors assert the need to set aside methodological preferences and encourage "qualitative" and "joint" research methodologies to facilitate theory generation (Schurink, 2003; Oppermann, 2000; Bryman, 1992; Rabinowitz \& Wessen, 1997). Daniels (1991) emphasises that the field of international management could benefit enormously from as-yet-unrealised synergies. To this end, and to accelerate theory development in international management, it may well be worthwhile to remind ourselves again of the need to dissolve the boundaries between qualitative and quantitative methods and turn our efforts to intellectual integration rather than separation. Carlie and Christensen (2004) explicitly make this link, arguing for an iterative cycle of theory building in which qualitative methods are used to observe social and human problems followed by quantitative methods to then test inductively formulated management theories. This point was made by Mendenhall et al (1993: 151) when they asserted, "perhaps those of us who work in the international management field should set aside our methodological differences, for if we do not, another decade may pass without significant progress toward the development of theory in the international management field."

Second, of concern in terms of the findings of this investigation are the relatively low numbers of "qualitative" and "joint" articles published during the period under review. These concerns are urgent given the recent body of work emphasising the culture-bound nature of management theory (e.g. Hofstede, 2001, House et al, 2004; Jackson, 2004;). Some argue that "local" (indigenous) efforts to engineer authentic theory development will continue to be unsuccessful until endogenous management systems are established and institutionalised (Tsui, 2004; Edoho, 2001). The latter observation is particularly significant for South African 
international management scholars suggesting that receptivity to qualitative methodology affords an opportunity for emic research rather than merely testing existing international management theories and constructs that may not capture local international management phenomena. Further, a number of authors indicate that managers working in a global context might experience disconnection between international management theory prescriptions and the imperatives of the local context unless international management theory is grounded in the realities of the local context (Ngambi, 2004; Horwitz, Kamoche \& Chew, 2002). Tsui (2004) asserts that much of management knowledge today is the product of scholarly work by researchers in North America and by scholars in Western Europe and this continued reliance may suggest researchers and educators could be disseminating a body of management knowledge more appropriate for countries inside North America and Western Europe than management knowledge grounded on realities inside the contexts and cultures of other nations. While it is necessary to prepare managers to be effective in a global economy, there is the concomittent need to explore and understand international management phenomenon within countries and cultures outside North America and Western Europe.

Qualitative methodologies provide researchers with a valuable tool in this regard because they assume a value-laden approach in terms of data that are collected and interpreted within the context in which it is generated. The contribution of South African scholars in this regard could greatly benefit the growth of the field, especially from an African context (Jackson, 2004). A recent article lamented the virtual absence of publications by African scholars in major management journals (Kirkman \& Law, 2005) calling for more publications from the continent. At the same time, Li and Tsui (2002) indicate there has been a relatively recent positive trend revealing entry barriers to non-North American studies in leading scholarly journals is decreasing. The reason for this is said to be two-fold: a higher level of open-mindedness by editors and reviewers towards studies involving non-North American samples and the improvement in quality of studies from other regions of the world.

Finally, the findings of this investigation necessitate reflection on a number of issues related to the low numbers of "qualitative" and "joint" research methodologies in published international management research. Indeed, the question could be asked: If "qualitative" and "joint" research is so important in theory building, why are so few international management researchers employing these methodologies? The answers to these questions are probably many and varied. However, there are some possible answers found in literature on the use of qualitative versus quantitative methodologies applicable to international management research as well (Marschan-Piekkari \& Welch, 2004). For example, a number of authors suggest that quantitative research is more likely to find acceptance in academic journals, because of a view statistical methods are often perceived as more "rigorous" and reliable while qualitative methodologies appear more open to bias and subjectivity (Argyris, 1980; Creswell, 2003; Lee, 1995; Marschan-Piekkari \& Welch, 2004; Strauss \& Corbin, 1990). Some scholars also point to the "ordeal" of interviewing via focus groups and structured interviews which are often very difficult to perform (e.g. Lee, 1995), often physically and emotionally draining (Harari \& Beaty, 1990) and actually frightening if participants' emotions are kindled (Denzin \& Lincoln, 2003; Garfinkle, 1985). A further reason could be that qualitative and field research can involve extraordinary logistical hurdles in establishing rapport and breaking down people's distrust, particularly when working with participants from diverse cultures and backgrounds (Triandis \& Gelfand 1998). Qualitative research necessitates some in-depth preliminary study of the history, culture, and language of the people whom one is investigating (Triandis, \& Gelfand, 1998). It also requires good interpersonal and group facilitation skills often not taught in doctoral programmes. Qualitative or a joint research method preclude a rapid gathering of aggregate data, and instead demands a longer-term commitment from the researcher (Miles \& Huberman, 1994). As such it is often not encouraged as a good career move for young scholars. 
In sum, the major findings of this investigation reveal that international management journals surveyed over the past sixteen years since 1991 are continuing to publish more articles employing quantitative relative to qualitative and joint research methods. While the present study suffers the limitation of not knowing the number of articles submitted with qualitative methods that may have been rejected, our empirical findings confirm Marschan-Piekkari and Welch's (2004) observation that qualitative research still remains a minority, even marginalised pursuit within the broad field of international business relative to quantitative approaches. There remains an epistemological preference for traditional positivist approaches to international management research (Cassell, Symon, Beuhring \& Johson, 2006). Future studies should continue to monitor the trends in research methods. At the same time, attention should be paid to monitoring whether the author representation of new theory development broadens to include scholars from regions of the world other than North America and Western Europe.

\section{References}

ARGYRIS, C (1980) The Inner Contradictions of Rigorous Research, New York: Harper and Row. BARKER, JR (1993) "Tightening the iron cage: Concertive control in self-managing teams", Administrative Science Quarterly, 38 (3 ): 408-437. BARLEY, SR(1986) “Technology as an occasion for structuring: Evidence from observations of CT scanners and the social order of radiology departments", Administrative Science Quarterly, 31 (1):78-108.

BEATY, DT; NKOMO, S \& KRIEK, HS (2006)

"Management theory building trends in South Africa:

An archival analysis", Management Dynamics, 15(2): 2-9. BEDEIAN, A (1989) "Totems and taboos:

Undercurrents in the management discipline",

Academy of Management Newsletter, October: 1-5. BOYACIGILLER, NA \& ADLER, NJ (1991) The parochial dinosaur: Organizational science in a global context", Academy of Management Review, 16(2): 262290.

BRYMAN, A (1992) "Quantitative and qualitative research: Further reflections on their integration", In J Brannan (ed.) Mixing Method: Qualitative and Quantitative Research, Hants, England: Avebury: 89111.
BUCKLEY, PJ (2002) "Is the international business research agenda running of out steam?" Journal of International Business Studies, 33(2): 365-373. CARLIE, PR \& CHRISTENSEN, CM (2005) "The cycles of theory building in management research", Unpublished manuscript.

CARMINES, EG \& ZELLER, RA (1991) Reliability and Validity Assessment, Newbury Park: Sage Publications.

CASSELL, C \& SYMON, G (2006) “Taking qualitative methods in organization and management research seriously", Qualitative Research in Organizations and Management: An International Journal, 1(1): 4-12. CASSELL, C; SYMON, G; BEUHRING, A \& JOHNSON, P (2006) "The role and status of qualitative methods in management research: An empirical account", Management Decision, 44(2): 290303.

CRESWELL, JW (2003) Research Design: Qualitative, Quantitative, and Mixed Methods Approaches, Thousand Oaks, CA: Sage Publications.

DANIELS, J (1991) "Relevance in international business research: A need for more linkages", Journal of International Business Studies, 22(2): 177-186. DENNIS, AR \& GARFIELD, M (2003) "The adoption and use of GSS in project teams: Towards more participative processes and outcomes", MIS Quarterly, 27(2): 289-317.

DENZIN, NK \& LINCOLN, YS (eds.) (2003) The Landscape of Qualitative Research: Theories and Issues, Thousand Oaks, CA: Sage Publications. DOKTOR, R; TUNG, RL \& VON GLINOW, MA (1991) "Incorporating international dimensions in management theory building", Academy of Management Review, 16(2): 259-261.

DREHER, A (2000) Foundations of Conceptual Research in Psychoanalysis, London: Karnac Books. DUTTON, JE \& DUKERICH, JM (1991) “Keeping and eye in the mirror: Image and identity in organisational adaptation", Academy of Management Journal, 34(3): 517-554.

EDEN, D \& RYNES, S (2003) "Publishing across borders: Furthering the internationalization of AMJ", Academy of Management Journal, 46(6): 679-683. EDOHO, F (2001) Management Challenges for Africa in the Twenty-First Century: Theoretical and Applied Perspectives, Westport, CT: Praeger.

EISENHARDT, K. (1989) "Building theories from case study research", Academy of Management Review, 14(4): 532-550.

GARFINKLE, H (1985) Studies in Ethnomethodology, Englewood Cliff, N.J.: Prentice-Hall.

GRAVETTER, EJ \& WALLNAU, LB (2000) Statistics for the Behavioural Science ( $5^{\text {th }}$ ed.) Belmont, CA: Wadsworth/Thomson. 
GREGERSON, HB; MORRISON, AJ \& BLACK, SJ (1998) "Developing leaders for the global frontier", Sloan Management Review, Fall: 21-22.

HARARI, O \& BEATY, DT (1990) "On the folly of relying solely on a questionnaire in cross-cultural research", Journal of Managerial Issues, 12(3): 24-32. HARZING, A (2008) "On becoming a high impact journal in international business and management", European Journal of International Management, 2(2): $115-118$.

HORWITZ, FM; KAMOCHE, K \& CHEW IKH (2002) "Looking east: Diffusing high performance work practices in the Southern Afro-Asian context", International Journal of Human Resource Management, 13(7): 1019-1041.

HOFSTEDE, G (1980) "Motivation, leadership and organization: Do American theories apply abroad?"

Organizational Dynamics, 9(1): 42-63.

HOFSTEDE, G (2001) Culture's Consequences:

Comparing Values, Behaviors, Institutions and

Organizations across Nations ( $2^{\text {nd }}$ ed.) Thousand Oaks,

CA: Sage Publications.

HOUSE, RJ; HANGES, PJ; JAVIDAN, M;

DORFMAN, P \& GUPTA, V (eds.) (2004) Leadership,

Culture and Organisations: The Globe Study of 62

Societies, Thousand Oaks, CA: Sage Publications, Inc.

JACK, GA; CALAS, MB; NKOMO, SM \&

PELTONEN, T (forthcoming) "Critique and international management: An uneasy relationship?", Academy of Management Review.

JACKSON, T (2004) Management and Change in Africa: A Cross-Cultural Perspective, London: Routledge.

JAVIDAN, M; STAHL, GS; BRODBECK, J \& WILDEROM, CPM (2005) "Cross-border transfer of knowledge: Cultural lessons from Project Globe", Academy of Management Executive, 19(2): 59-76. KIRKMAN, B \& LAW, K (2005) "International management research in AMJ: Our past, present, and future", Academy of Management Journal, 48(3): 377-386.

LEE, TW (1995) Using Qualitative Methods in Organisational Research, Thousand Oaks: Sage. LEVY, O; BEECHLER, S; TAYLOR, S \& BOYACIGILLER, NA (2007) "What we talk about when we talk about 'global mindset': Managerial cognitions in multinational corporations", Journal of International Business Studies, 38(2): 231-258. LEWIS, RD (2000) When Cultures Collide, London: Nicholas Brealey Publishing Ltd.

LI, JT \& TSUI, A (2002) "A citation analysis of management and organisation research in the Chinese context: 1984 to 1999", Asia Pacific Journal of Management, 19(1): 87-107.
MARSCHAN-PIEKKARI, R \& WELCH, C (eds.) (2004) Handbook of Qualitative Research Methods for International Business, Cheltenham, UK: Edward Elgar.

MENDENHALL, M; BEATY, DT \& ODDOU, G (1993) Where have all the theorists gone? An archival review of the international management literature, International Journal of Management, 10(2): 146-153. MILES, M \& HUBERMAN, M (1994) Qualitative Data Analysis, Thousand, Oaks, CA: Sage Publications. MORSE, J (2004) "Constructing qualitatively derived theory: Concept construction and concept typologies", Qualitative Health Research, 14(10): 1387-1395.

NGAMBI, HC (2004) "African leadership: Lessons from the chiefs", In TA Meyer \& I Boninelli (eds.) Conversations in Leadership: South African Perspectives, Johannesburg: Knowledge Resources, p. 107-132. PETERSON, RB (2004) "Empirical research in international management: A critique and future agenda”, In R Marschan-Piekkari \& C Welch (eds.) Handbook of Qualitative Research Methods for International Business, Cheltenham, UK: Edward Elgar. p. 25-55.

OPPERMANN, M (2000) "Triangulation: A methodological discussion", International Journal of Tourism Research, (2)2: 141-147.

PORTER, LW (1996) "Forty years of organisation studies: Reflections from a micro perspective", Administrative Science Quarterly, 41(2 ): 262-269 RABINOWITZ, VC \& WESSEN, S (1997)

"Elu(ci)d(at)ing epistemological impasses: Re-viewing the qualitative/quantitative debates in psychology", Journal of Social Issues, 53(4): 605-631.

SCHOLLHAMMER, H (1975) "Current research in international and comparative management issues", Management International Review, 15(2): 29-45 SCHURINK, WJ (2003) "Qualitative research in management and organisational studies with reference to recent South African research", SA Journal of Human Resource Management, 1(3): 2-14.

SHENKAR, O (2004) "One more time: International business in a global economy", Journal of International Business Studies, 35(2): 161-171.

STRAUSS, AL \& CORBIN J (1990) Basics of Qualitative Research: Grounded Theory Procedures and Techniques, Newbury Park, CA: Sage. SYMON, G \& CASSELL, C (1998) Qualitative Methods and Analysis in Organizational Research, London: Sage Publications.

TRIANDIS, HC \& GELFAND, MJ (1998)

"Converging measurement of horizontal and vertical individualism and collectivism", Journal of Personality and Social Psychology, 74(2): 118-128. 
TSANG, EW \& KWAN, KM (1999) "Replication and theory development in organisational science: A critical realist perspective", Academy of Management Review, 24(4): 759-780.

TSUI, AS (2004) "Contributing to global management knowledge: A case for high quality indigenous

research", Asia Pacific Journal Of Management, 21(4): 491-513

VAN DE VEN, AH (1989) "Nothing is quite so practical as a good theory", Academy of Management Review, 14(4): 486-9.

VAN FLEET, D \& BEARD, JW (1988) "Lessons for management research from the history of science", Paper presented at the annual Academy of Management Meeting. Anaheim, California: August 10.
VAN MAANEN, J; SORENSEN, J \& MITCHELL,

T (2007) "The interplay between theory and method", Academy of Management Review, 32(4): 1145-1154.

WEICK, KE (1989) Theory construction as disciplined imagination. Academy of Management Review. 14(4):

516-31.

WERNER, S (2002) Recent developments in international management research: A review of 20 top management journals, Journal of Management, 28 (3): 277-305.

WESTWOOD, R \& LINSTEAD, S (eds.) (2001) The Language of Organizations, Thousand Oaks, CA: Sage. WHITE, S (2002) Rigor and relevance in Asian management research: Where are we and where can we go? Asia Pacific Journal of Management, 19(2/3): 87-352. 